Table 1. Sedimentation and diffusion constants of peroxidase

\begin{tabular}{|c|c|c|c|c|c|c|}
\hline $\begin{array}{l}\text { Concen- } \\
\text { tration } \\
\text { (mg./ml.) }\end{array}$ & $\begin{array}{l}S_{20} \text { (corr.) } \\
\left(\times 10^{13}\right)\end{array}$ & $\begin{array}{c}D_{20} \text { (corr.) } \\
\left(\times 10^{7}\right)\end{array}$ & $\bar{V}$ & $M$ & $f / f_{0}$ & $\begin{array}{l}\text { Proportion } \\
\text { in main } \\
\text { boundary }\end{array}$ \\
\hline $\begin{array}{l}7 \cdot 7 \\
3.4\end{array}$ & $\begin{array}{l}\mathbf{3} \cdot 47 \\
\mathbf{3} \cdot 48\end{array}$ & $\overline{7.05}$ & $\overline{0.699}$ & $\overline{39,800}$ & $\overline{1 \cdot 36}$ & $\begin{array}{c}0.92 \\
-\end{array}$ \\
\hline
\end{tabular}

Theorell (1942) has reported sedimentation and diffusion measurements on peroxidase : our value for $S_{20}$ (corr.) is about $10 \%$ lower than his $\left(3.85 \times 10^{-13}\right)$ (cf. Cecil \& Ogston, 1948), while our value for $D_{20}$ (corr.) agrees fairly well with his value of $6.84 \times 10^{-7}$.
Our value for the molecular weight is lower than Theorell's $(44,100)$, but is in agreement with that calculated by Keilin \& Hartree (1951) from the haematin content; the chief uncertainty in our quantity probably lies in the value of $\bar{V}$.

\title{
REFERENCES
}

Cecil, R. \& Ogston, A. G. (1948). Biochem. J. 43, 592.

Coulson, C. A., Cox, J. T., Ogston, A. G. \& Philpot, J. St L. (1948). Proc. roy. Soc. A, 192, 382.

Kegeles, G. \& Gosting, L. J. (1947). J. Amer. chem. Soc. 69, 2516.
Keilin, D. \& Hartree, E. F. (1951). Biochem. J. 49, 88.

Philpot, J. St L. (1938). Nature, Lond., 141, 283.

Philpot, J. St L. (1939). Biochem. J. 33, 1707.

Theorell, H. (1942). Ark. Kemi Min. Geol. B, 15, no. 24.

\section{Studies on the Enzymic Synthesis of Glutamine}

\author{
By W. H. ELLIOTT \\ Biochemical Laboratory, University of Cambridge
}

(Received 5 September 1950)

Earlier reports described the discovery of an enzyme system in sheep brain which synthesizes glutamine in the presence of L-glutamic acid, adenosinetriphosphate (ATP) and ammonia (Elliott, 1948; Elliott \& Gale, 1948). The present paper deals with the purification and detailed study of this enzyme system and the results of a distribution survey. A summary of this work was presented at the First International Congress of Biochemistry at Cambridge in August 1949 (Elliott, 1949). Speck $(1947,1949 a, b)$ has independently reported a study of the glutamine-forming system present in pigeon liver.

\section{MATERIALS}

ATP was prepared as described by Needham (1942) except that in the final stages the method of Kerr (1941) was adopted to produce the monobarium salt. This was converted to the $\mathrm{Na}$ salt by dissolving it in $\mathrm{N}-\mathrm{HCl}$ and adding a slight excess of $\mathrm{Na}_{2} \mathrm{SO}_{4}$. After centrifuging, the supernatant was neutralized to $\mathrm{pH} 6.8$ and stored at $-10^{\circ}$. The solution used contained $0 \cdot 1 \mathrm{mg}$. inorganic $P / \mathrm{ml}$. and $4.3 \mathrm{mg}$. of $P$ hydrolysed by boiling $\mathrm{N}-\mathrm{HCl}$ in $10 \mathrm{~min}$. (acid-labile $\mathrm{P}$ ). The solution was analysed enzymically by the method of Bailey (1949). The percentages of the acid-labile $P$ hydrolysed by myosin, by myosin + myokinase, and by inorganic pyrophosphatase were $45 \cdot 6,91 \cdot 2$ and $2 \cdot 6$ respectively.

Adenosinediphosphate (ADP) was prepared from ATP by the method of Bailey (1942). The Ba salt was treated in the same way as that for ATP. The solution used contained $3.16 \mathrm{mg}$. of total $\mathrm{P} / \mathrm{ml}$., of which $50 \%$ was hydrolysed by boiling $\mathrm{N}-\mathrm{HCl}$ in $10 \mathrm{~min}$. The percentages of the total $\mathrm{P}$ split by myosin alone, by myosin + myokinase, and by inorganic pyrophosphatase were $1 \cdot 0,47$ and $0 \cdot 02$ respectively. Adenylic acid (AA) was supplied by the Armour Laboratories, Chicago.

L-Glutamic acid hydrochloride, hydroxylamine hydrochloride and hydrazine sulphate were commercial samples twice recrystallized from water. All solutions were neutralized before use.

Methylamine hydrochloride was prepared free from $\mathrm{NH}_{4} \mathrm{Cl}$ by the method of François (1907). A large excess of yellow $\mathrm{HgO}$ was used to make sure that all traces of $\mathrm{NH}_{3}$ were removed.

DL-Methionine oxide was prepared by the method of Toennies \& Kolb (1939).

D-Glutamic acid, $N$-carbobenzyloxy-L-glutamic acid, Lisoglutamine (L-glutamic acid $\alpha$-amide), and L-glutamine were kindly given by Dr A. C. Chibnall.

Phosphate buffers were mixtures of $\mathrm{Na}_{2} \mathrm{HPO}_{4}$ and $\mathrm{KH}_{2} \mathrm{PO}_{4}$.

Glyoxaline buffers were prepared by adjusting the $\mathrm{pH}$ of solutions of the base with HCl.

\section{METHODS}

Incubations were usually performed in open tubes at $30^{\circ}$ and samples taken as necessary for estimations.

\section{Chemical determinations}

Hydroxamic acid was estimated by the method of Lipmann \& Tuttle (1945) except that determinations were done on $4.5 \mathrm{ml}$. samples as described previously (Elliott \& Gale, 1948). 
Ammonia. Samples were deproteinized by mixing with 0.2 vol. of $25 \%(w / v)$ aqueous trichloroacetic acid and centrifuging. The supernatant was neutralized to $\mathrm{pH} 6.8$ and a suitable portion taken for distillation of $\mathrm{NH}_{3}$ in the Parnas \& Heller apparatus. The $\mathrm{NH}_{3}$ in the distillate was determined colorimetrically after nesslerization.

Glutamine was estimated according to the method described by Krebs (1935).

Phosphate was estimated by the method of Fiske \& Subbarow (1925).

Elementary analyses were by Drs Weiler and Strauss of Oxford.

\section{Preparation of enzyme-containing extracts}

Purification of the glutamine-synthesizing system of sheep brain. The standard test system for estimating enzymic activity contained the following mixture: $0.2 \mathrm{M}$-glyoxaline buffer (pH 7.1), $1.0 \mathrm{ml}$; 1.0 M-sodium L-glutamate, $0.5 \mathrm{ml}$; sodium adenosinetriphosphate $(4.0 \mathrm{mg}$. $\mathrm{Pl} / \mathrm{ml}),. 1.0 \mathrm{ml}$; 1.0 M-neutralized $\mathrm{NH}_{2} \mathrm{OH}$. $\mathrm{HCl}, 0.2 \mathrm{ml}$.; $1 \cdot 0 \mathrm{M}-\mathrm{MgCl}_{2}, 0.2 \mathrm{ml}$.; enzyme solution + water, $1.4 \mathrm{ml}$. The tubes were incubated at $30^{\circ}$ for $15 \mathrm{~min}$. and the hydroxamic acid was then estimated. Under these conditions the hydroxamic acid production was proportional to the amount of enzyme added up to a value of about $4 \mu \mathrm{g} . \mathrm{mol}$. hydroxamic acid. It was not possible at this stage to use the more accurate method of estimating enzymic activity by means of phosphate liberation from ATP owing to the high adenosinetriphosphatase (ATPase) activity in the crude extracts.

Acetone-dried grey matter of sheep brain was extracted with 10 vol. of distilled water for $10 \mathrm{~min}$. with very gentle stirring. After centrifuging, the supernatant was filtered through cotton wool, cooled to $4^{\circ}$ and mixed with $0 \cdot 2$ vol. of $0 \cdot 1 \mathrm{M}$-sodium acetate buffer ( $\mathrm{pH} 4 \cdot 2)$. The precipitate was centrifuged down, washed twice by suspending in cold distilled water and centrifuging, and finally redissolved in water (half the original volume of extract) by adjusting the $\mathrm{pH}$ to 6.8 with a little $\mathrm{NaOH}$. This gave a fourfold purification on a nitrogen basis with a recovery of $70 \%$. The extract was almost completely free from ATPase activity. Further purification up to 19-fold was achieved by heating the solution in the presence of $0.2 \mathrm{M}$-acetate buffer ( $\mathrm{pH} \mathrm{4.4)}$ and $0 \cdot 1 \mathrm{M}-\mathrm{MgCl}_{2}$ at $43^{\circ}$ for $3 \mathrm{~min}$. The precipitate was removed by centrifuging and the enzyme adsorbed on to calcium phosphate gel, followed by elution with $0 \cdot 2 \dot{\mathrm{M}}$ phosphate buffer (pH 7.2).

The stability of the enzyme appeared to decrease as purification proceeded and for this reason it was convenient to use the enzyme at the first stage of purification; this was stable for 2 weeks when stored at $0^{\circ}$.

Bacterial extracts. Extracts of Staphylococcus aureus were prepared as described previously (Elliott \& Gale, 1948). Extracts of baker's yeast were obtained in the same manner.

Kidney extracts. Acetone-dried rabbit kidney was extracted and purified in the same way as described for brain.

Mealworm extracts. Mealworms (Tenebrio molitor) were ground with distilled water in a mortar and the thick suspension centrifuged. The cloudy supernatant was used in experiments.

Plant extracts. Seeds of Lupinus albus and L. angustifolius were soaked in distilled water and kept to germinate in moist peat for 3-5 days. The seedlings were washed, the seed coats removed and the whole seedlings ground with sand in a mechanical mortar. The mush was squeezed through muslin and the extract centrifuged. The turbid supernatant was dialysed against dilute phosphate buffer (pH 7·1).

Adenylic acid deaminase. The preparation used consisted of a freeze-dried preparation of the fraction precipitated from a dialysed rabbit-muscle extract on addition of $0.1 \mathrm{vol}$. of ethanol (Askonas, 1950). I am grateful to Miss I. A. Askonas for this preparation.

\section{RESULTS}

\section{Enzymic synthesis of glutamine by brain extract}

Fig. 1 shows the formation of glutamine by the purified brain extract in the presence of ATP, Lglutamate, ammonia and $\mathrm{Mg}^{++}$. The synthesis is

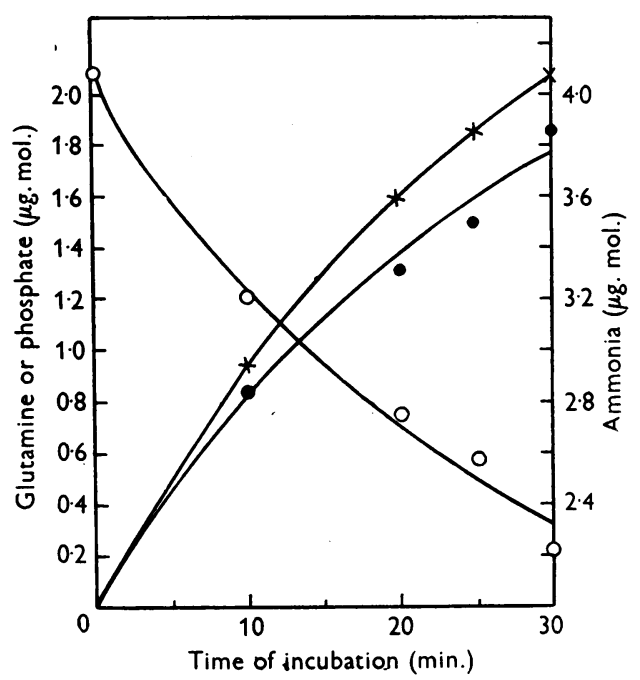

Fig. 1. Synthesis ' of glutamine from L-glutamate and ammonia by extract of sheep brain. -O, Glutamine formed; $x-x$, inorganic phosphate; $O-O$, free ammonia.

accompanied by the disappearance of free ammonia and the liberation of phosphate from ATP. The ratio of phosphate liberated to amide formed is about $\mathbf{1 \cdot 1}$; this may be due to a slight hydrolysis of glutamine during estimation.

\section{Isolation of glutamine}

A large-scale experiment was performed so that the glutamine formed could be identified by isolation. The mixture contained 0.04 M-phosphate buffer (pH 7.0); 0.1 M-sodium L-glutamate; 0.02 Mmagnesium chloride; 0.014 M-ATP; $0.02 \mathrm{M}$-ammonium chloride; $0.2 \mathrm{~g}$. purified myokinase; $0.1 \mathrm{~g}$. 
(approx.) of a muscle AA-deaminase preparation; $70 \mathrm{ml}$. of purified brain extract. The total volume was $225 \mathrm{ml}$. Myokinase and AA-deaminase were added to remove the ADP which is formed during the synthesis of glutamine. The mixture was incubated at $30^{\circ}$ in the presence of a few drops of toluene for $20 \mathrm{hr}$. After incubation glutamine was isolated by the method of Vickery, Pucher \& Clark (1936) from the stage of adding lead acetate. The product was obtained as colourless crystals and recrystallized twice from $66 \%(v / v)$ aqueous ethanol. This gave $0.35 \mathrm{~g}$. of a product which contained $71 \%$ glutamine

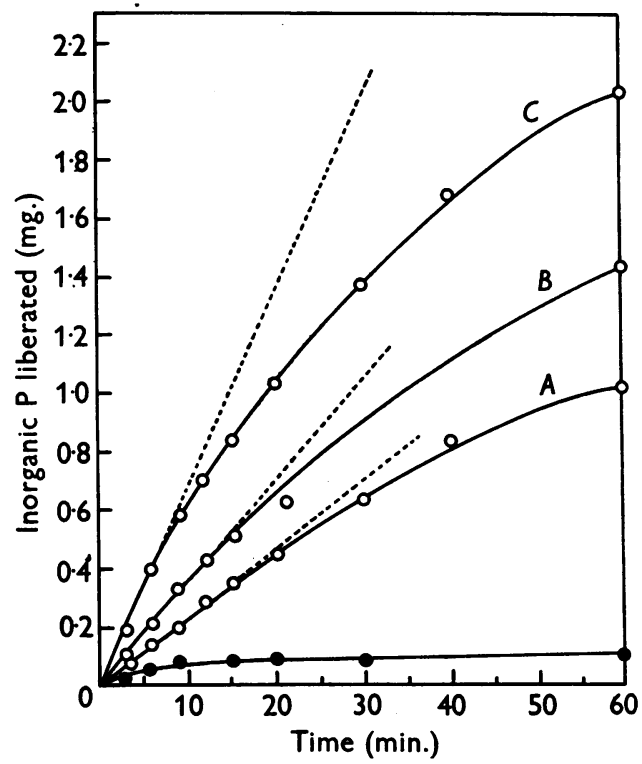

Fig. 2. Progress curves of glutamine synthesis in the presence of different concentrations of enzyme. - ..., Initial velocities. Volumes of enzyme solution added: control and curve $C, 1.0 \mathrm{ml}$.; curve $A, 0.33 \mathrm{ml}$; curve $B$, $0.5 \mathrm{ml}$. - - , Control without glutamic acid. Curves $A, B$ and $C$ have been corrected by subtraction of the control values.

as estimated by amide $\mathrm{N}$. (Found: C, 38.4; H, 6.5; $\mathrm{N}, 16 \cdot 5$; acid-labile amide $N, 6 \cdot 9$. Calc. for $\mathrm{C}_{5} \mathrm{H}_{10} \mathrm{O}_{3} \mathrm{~N}_{2}$ : $\mathrm{C}, 41.1 ; \mathrm{H}, 6.9 ; \mathrm{N}, 19.2$; amide $\mathrm{N}, 9.5 \%$.) The analysis suggests that some of the impurity was glutamic acid (calculated $\mathbf{N}$ for such a mixture is $16 \cdot 4 \%$ ). Analysis by paper chromatography showed the presence of glutamine and a smaller amount of glutamic acid. When mixed with glutamine isolated from sugar beet by the method of Vickery et al. (1936) only the same two spots appeared on the paper. The preparation was free from ammonia; a solution gave no initial colour with Nessler reagent, but the colour slowly developed as described by Archibald (1945) for glutamine.

\section{Properties of the brain enzyme system}

Measurement of activity. The liberation of inorganic phosphate from ATP in the presence of Lglutamate and ammonia was chosen as the most accurate and convenient method of determining enzyme activity. The complete incubation mixture contained the following final concentrations : $0.04 \mathrm{M}$ glyoxaline buffer (pH 7.1); 0.02M-magnesium chloride; $0 \cdot 1 \mathrm{M}$-sodium L-glutamate; 0.014M-sodium salt of ATP; enzyme solution, $1 \mathrm{ml}$. The final vol. was $10 \mathrm{ml}$. Unless otherwise stated, the above conditions were used in all subsequent experiments and

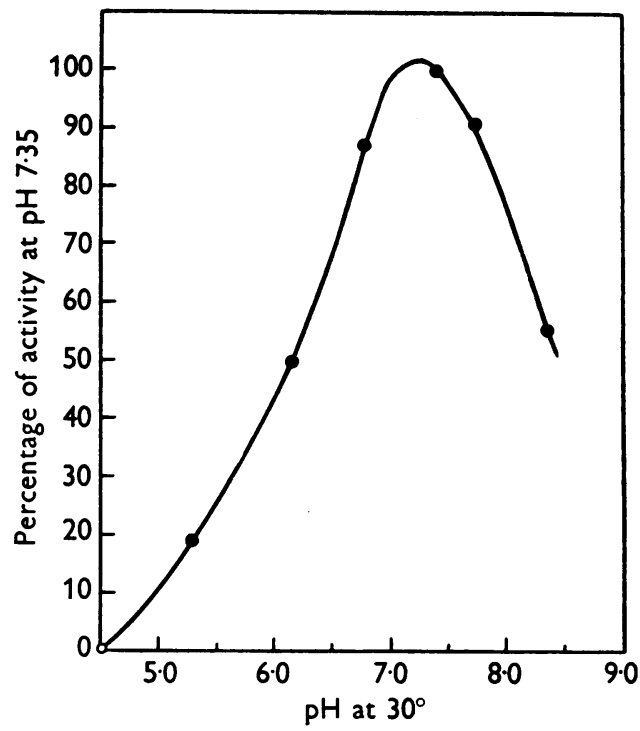

Fig. 3. The effect of $\mathrm{pH}$ on the rate of glutamine synthesis. Glyoxaline buffer was used for all except the lowest $\mathrm{pH}$ where acetate was used.

only variations of this will be described. Control experiments in which glutamate was omitted from the incubation mixture were carried out in each case to obtain the corrections necessary for ATPase activity; these control values were never more than. about $5 \%$ of the maximum enzyme activity with respect to glutamine synthesis. All curves shown in the figures are corrected for ATPase activity though in some cases the latter is shown for comparison. Fig. 2 shows the progress of the reaction in the presence of different amounts of enzyme. In the absence of glutamate the increase in phosphate was very small. With the complete system, liberation of phosphate was linear only until $0.04 \mathrm{mg}$. P/ml. had been liberated, after which the reaction velocity decreased. Since this represents less than $10 \%$ breakdown of the ATP present, the decreased rate of reaction cannot be accounted for by exhaustion of substrate. The slopes of the linear portions of the 
curves are proportional to the amount of enzyme added and in all subsequent experiments care was taken to ensure that activity measurements fell on the linear part so that the true initial reaction velocity was obtained.

Effect of $\mathrm{pH}$. The optimum $\mathrm{pH}$ for the enzymic synthesis of glutamine lies at about 7.2 (Fig. 3).

Effect of substrate concentrations. The activity of the enzyme system increases with higher concentrations of ATP (Fig. 4). The effect appears to be

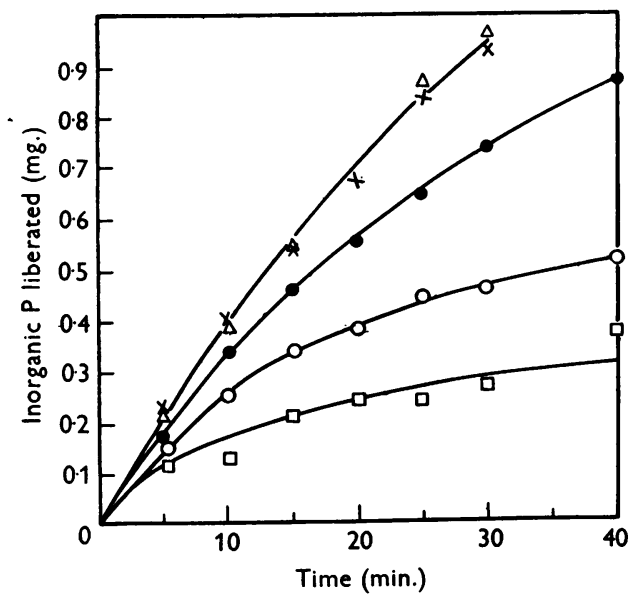

Fig. 4. The effect of concentration of adenosinetriphosphate on the rate of glutamine synthesis. $\square-\square, 0.0017 \mathrm{M}$; $\mathrm{O} \mathrm{O}, 0.0035 \mathrm{M}$; $\bigcirc, 0.007 \mathrm{M} ; \mathrm{x}-\mathrm{x}, 0.014 \mathrm{M}$; $\triangle-\triangle, 0.026 \mathrm{M}$.

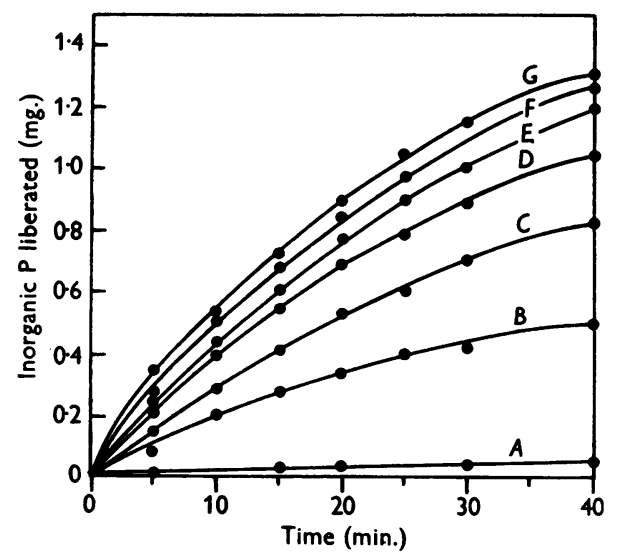

Fig. 5. The effect of glutamate concentration on the rate of glutamine synthesis. The concentrations of sodium Lglutamate used for curves $A-G$ were $0,0.002,0.005,0.01$, $0.025,0.05$ and $0.1 \mathrm{M}$, respectively.

more complex than that of a simple enzyme-substrate relationship, for the higher levels of ATP appear to act by maintaining the linear rate of reaction for a longer period of time rather than by increasing the initial rate of reaction, even though the fall in reaction velocity occurs when only a small proportion of the ATP has been used. This effect is

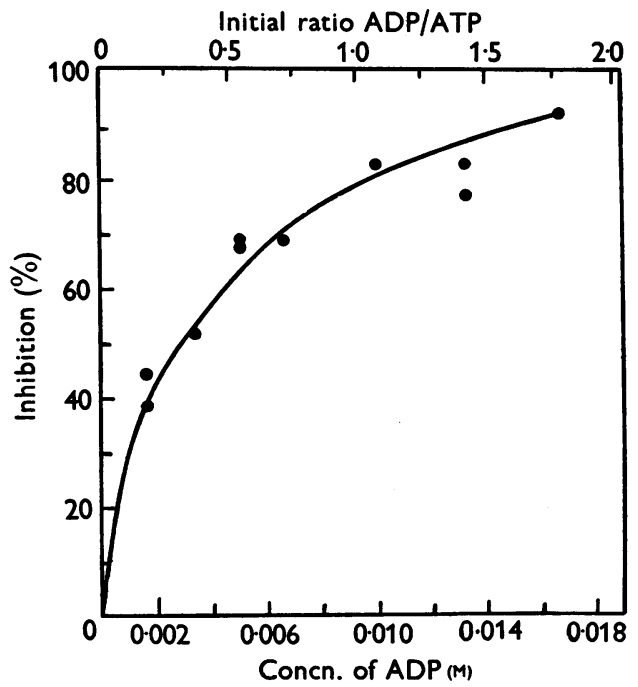

Fig. 6. Inhibition of the synthesis of glutamine by adenosinediphosphate. The concentration of ATP in all experiments was $0 \cdot 0093 \mathrm{M}$.

Table 1. The effect of adenosinetriphosphate (ATP) concentration on the inhibition by adenosinediphosphate $(A D P)$ of glutamine synthesis by sheep. brain extract

(Incubation mixture as described in text.)

$\begin{array}{cccc}\begin{array}{c}\text { Concn. } \\ \text { of ADP } \\ (M)\end{array} & \begin{array}{c}\text { Concn. } \\ \text { of ATP } \\ (\mathbf{M})\end{array} & \begin{array}{c}\text { P liberated } \\ \text { in } 10 \text { min./10 ml. } \\ \text { of incubation fluid } \\ \text { (mg.) }\end{array} & \begin{array}{c}\text { Inhibition } \\ (\%)\end{array} \\ 0 & 0.005 & 0.27 & - \\ 0 & 0.009 & 0.29 & - \\ 0 & 0.019 & 0.29 & - \\ 0.0034 & 0.005 & 0.10 & 64 \\ 0.0034 & 0.007 & 0.13 & 55 \\ 0.0034 & 0.009 & 0.16 & 45 \\ 0.0034 & 0.012 & 0.17 & 41 \\ 0.0034 & 0.014 & 0.14 & (48) \\ 0.0034 & 0.019 & 0.17 & 41\end{array}$

Table 2. Inhibition of glutamine synthesis in sheep-brain extract by adenylic acid $(A A)$

(Incubation mixture as described in text.)

$\begin{array}{cccc}\begin{array}{c}\text { Concn. } \\ \text { of AA }\end{array} & \begin{array}{c}\text { Concn. } \\ \text { of ATP } \\ \text { (M) }\end{array} & \begin{array}{c}\text { P liberated } \\ \text { in 10 min./10 ml. } \\ \text { of incubation fluid } \\ \text { (mg.) }\end{array} & \begin{array}{c}\text { Inhibition } \\ (\%)\end{array} \\ 0 & 0.014 & 0 \cdot 29 & - \\ 0.01 & 0.014 & 0 \cdot 24 & 17 \\ 0.04 & 0.014 & 0.23 & 20\end{array}$

more clearly seen when the curves in Fig. 4 are compared with those obtained with varying levels of glutamate (Fig. 5). In the latter the initial rates of 
reaction change with substrate concentration, but the overall shapes of the curves remain unchanged. This effect of ATP concentration on the shape of the progress curve is probably due to the higher concentrations overcoming the inhibition by the ADP which is formed during the synthesis of glutamine. As shown in Fig. 6, ADP is a very powerful inhibitor of the brain system. When the ratio of ADP/ATP is 0.3 a $50 \%$ inhibition is obtained. The inhibition by ADP is reduced by increasing the concentration of ATP (Table 1) suggesting competitive inhibition. AA has only a small effect (Table 2); even when the AA/ATP molecular ratio exceeds 1.0 the activity falls by only $20 \%$. This small inhibition could be due to the formation of ADP from AA and ATP by traces of myokinase in the enzyme preparation.

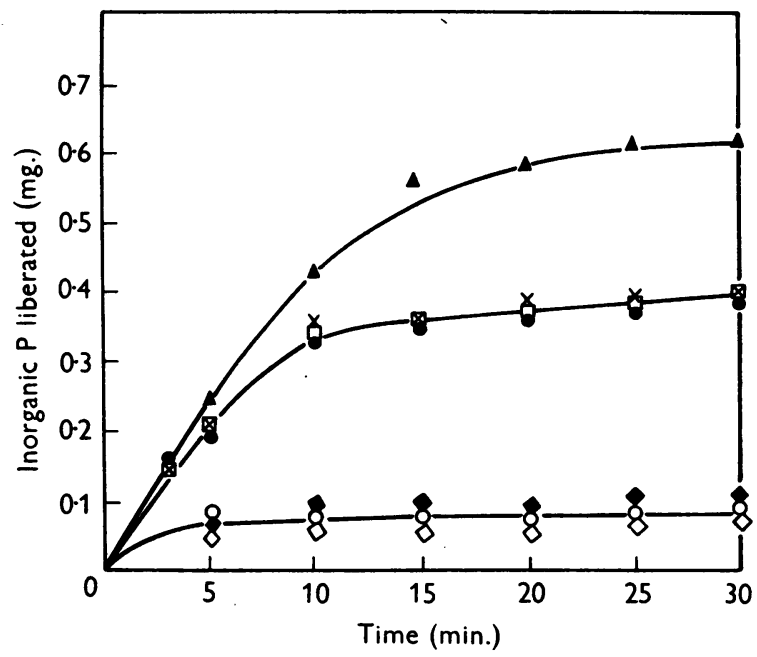

Fig. 7. Enzyme activity in the presence of various amino compounds. $\mathrm{O}-\mathrm{O}$, Control without added base; $\diamond-\diamond, 02 \mathrm{M}$-methylamine; $\diamond-\diamond, 0.001 \mathrm{M}$-methylamine; $x-x, 0.001 \mathrm{M}$-ammonium chloride; -0 , 0.001 M-L-hydroxylamine; $\square-\square, 0.001$ M-hydrazine; $\Delta-\Delta, 0.0015 \mathrm{M}$-ammonium chloride.

Specificity towards L-glutamate. D-Glutamate, Lisoglutamine, L-glutamine, $N$-carbobenzyl oxy-Lglutamate, L-aspartate and nicotinic acid were all inactive in this system.

Specificity towards 'glutamyl acceptors'. Fig. 7 shows the results of a series of experiments in which the effect of replacing ammonia by other bases was studied. In the presence of glutamate, but without added ammonia, a small liberation of phosphate occurred during the first $7 \mathrm{~min}$. This increase was approximately equivalent to the amount of free ammonia present as a contaminant in the enzyme preparation (about $0.3 \mu \mathrm{g}$. mol./ml.). With the addition of $0.001 \mathrm{M}$-ammonium chloride, phosphate liberation proceeded rapidly until the increase in phosphate was equivalent to the ammonia added.
With half as much again of ammonium chloride $(0.0015 \mathrm{M})$, the initial rate of reaction was about the same, but the final level of phosphate reached was higher. When ammonium chloride was replaced by $0.001 \mathrm{~m}$-hydroxylamine or hydrazine the reaction curves were the same as that with the same concentration of ammonium chloride. The addition of methylamine, even in concentrations as high as $0.02 \mathrm{M}$, caused no significant increase in phosphate production, showing that this compound does not condense with glutamic acid in this system. This is in contrast to the result obtained by Speck $(1949 b)$ who found methylamine to react at about the same rate as ammonium chloride in the glutamine-synthesizing system of pigeon liver. This may be due to different specificities of the systems from different tissues, though it must be pointed out that Speck used commercial samples of methylamine which may con-

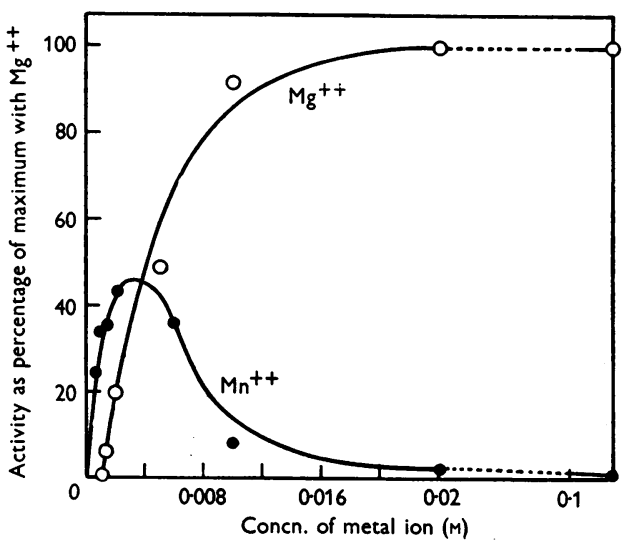

Fig. 8. The effect of concentration of $\mathrm{Mg}^{++}$and $\mathrm{Mn}^{++}$ ions on the enzymic synthesis of glutamine.

tain sufficient ammonium chloride to react in the presence of the enzyme system. As shown in Fig. 7, methylamine does not inhibit the reaction with the residual ammonia present in the enzyme preparation. From the progress curves a rough estimate of the $K_{m}$ towards ammonia, hydroxylamine and hydrazine gives a value of $0.0005 \mathrm{M}$. The following amino compounds were inactive as glutamyl acceptors: ethanolamine, urea, glycine, glycine ethyl ester, $p$-aminobenzoic acid, aniline, phenylhydrazine, $\beta$-phenylisopropylamine and L-glutamine.

Effect of metallic ions. The purified brain enzyme system is completely inactive in the absence of $\mathrm{Mg}^{++}$ or $\mathrm{Mn}^{++} . \mathrm{Mg}^{++}$gives maximal activation at $0.02 \mathrm{M}$ (Fig. 8); at low concentrations $\mathrm{Mn}^{++}$is as effective as $\mathrm{Mg}^{++}$, but at concentrations of $\mathrm{Mn}^{++}$greater than $0.003 \mathrm{M}$ the activity falls rapidly (Fig. 8). The maximal activation by $\mathrm{Mn}^{++}$is only $46 \%$ of that given by $0.02 \mathrm{M}-\mathrm{Mg}^{++}$. 
$\mathrm{Ca}^{++}$strongly inhibits the synthesis of glutamine, but this inhibition is reduced by increasing the concentration of $\mathrm{Mg}^{++}$(Table 3) suggesting that the $\mathrm{Ca}^{++}$competes with the $\mathrm{Mg}^{++}$in the enzyme system.

Table 3. The effect of $\mathrm{Mg}^{++}$on the inhibition of glutamine synthesis in brain extracts by $\mathrm{Ca}^{++}$

(Incubation mixture as described in text.)

$\begin{array}{cccc}\begin{array}{c}\text { Concn. } \\ \text { of } \begin{array}{c}\mathrm{Mg}^{++} \\ (\mathrm{M})\end{array}\end{array} & \begin{array}{c}\text { Concn. } \\ \text { of } \mathrm{Ca}^{++} \\ (\mathrm{M})\end{array} & \begin{array}{c}\text { P liberated } \\ \text { in 10 min./10 ml. } \\ \text { of incubation fluid } \\ (\mathrm{mg} .)\end{array} & \begin{array}{c}\text { Inhibition } \\ (\%)\end{array} \\ 0.01 & 0 & 0.36 & - \\ 0.01 & 0.01 & 0.024 & 93 \\ 0.02 & 0.01 & 0.037 & 90 \\ 0.10 & 0.01 & 0.16 & 56\end{array}$

Inhibitors. Fluoride is the most powerful inhibitor so far found for the brain glutamine-synthesizing system; $50 \%$ inhibition is given by $5 \times 10^{-5} \mathrm{M}$ sodium fluoride (Fig. 9). $p$-Chloromercuribenzoate

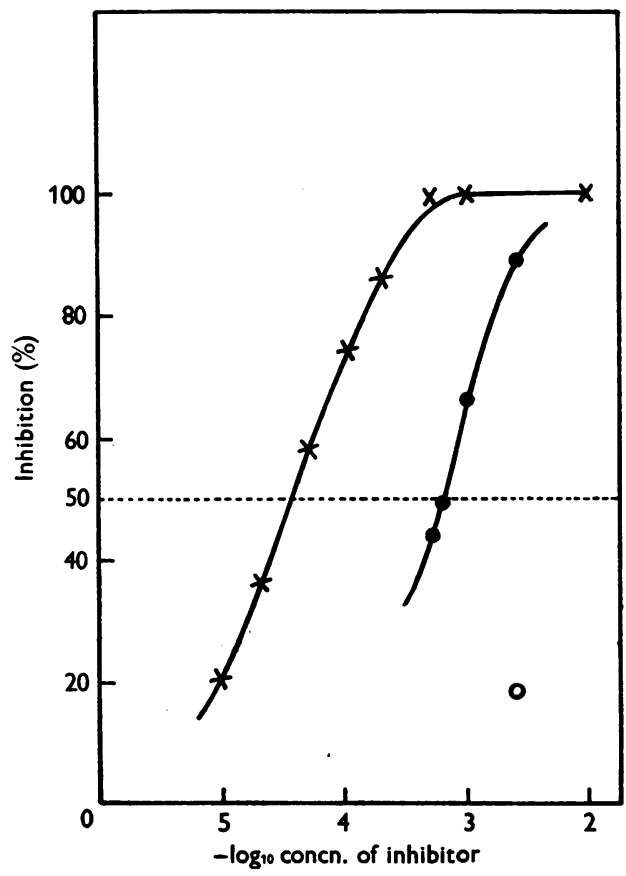

Fig. 9. Inhibition of the glutamine-forming system by fluoride and $p$-chloromercuribenzoate. $x-x$, Fluoride; - - , $p$-chloromercuribenzoate. The single open circle shows the effect of adding $0.02 \mathrm{M}$-cysteine before adding the $p$-chloromercuribenzoate.

inhibits $50 \%$ at a concentration of $10^{-3} \mathrm{M}$, though this inhibition is largely abolished by the prior addition of cysteine (Fig. 9). In the absence of inhibitor cysteine has no activating effect and, in fact, over long periods of incubation has a slight

inhibitory action which may be due to the formation of cystine by oxidation.

The sulphoxide derived from methionine, which inhibits the glutamine-forming system of Staphylococcus aureus (Elliott \& Gale, 1948), also inhibits the brain preparation, but the latter is about ten times less sensitive (Fig. 10).

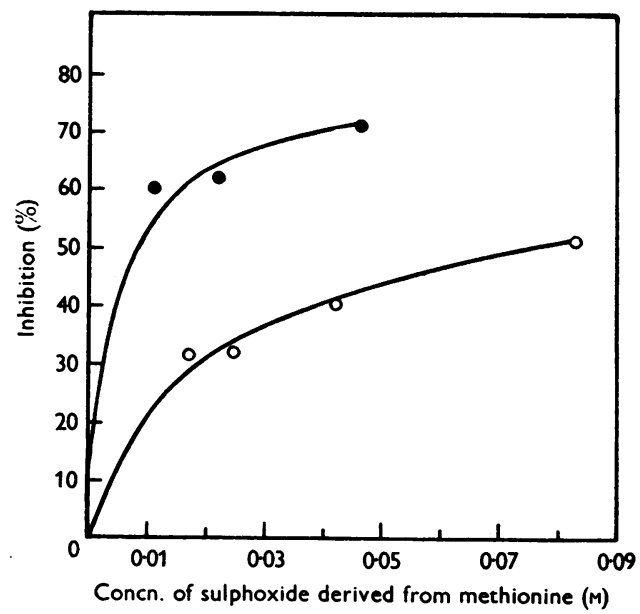

Fig. 10. Inhibition of glutamine synthesis in extracts from sheep brain and Staphylococcus aureus by the sulphoxide derived from methionine. - - Staph. aureus; $\mathrm{O}-\mathrm{O}$, brain.

Crystal violet, which completely inhibits the bacterial system (Elliott \& Gale, 1948), has no effect on the brain system even at a concentration as high as $0.004 \mathrm{M}$.

Distribution. The formation of a hydroxamic acid in the presence of L-glutamate, ATP and hydroxylamine was used as a test for the presence of the

Table 4. Synthesis of glutamyl-hydroxamic acid by extracts of Lupinus albus seedlings

(For details of incubation mixture, see text.)

Incubation mixture

Complete system No ATP

No glutamate

No magnesium

With 0.001 M-NaF

Boiled enzyme

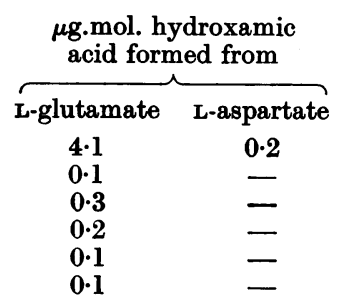

glutamine-synthesizing system. Positive results were obtained with cell-free extracts of baker's yeast, rabbit kidney, mealworms (Tenebrio molitor) and seedlings of $L$. albus and $L$. angustifolius. The activity $/ \mathrm{ml}$. in the plant extracts was higher than that in crude brain extracts. The plant system resembled that of animal tissues in being activated 
by $\mathrm{Mg}^{++}$and inhibited by low concentrations of fluoride (Table 4). It was not possible to detect any formation of a hydroxamic acid when glutamate was replaced by L-aspartate.

Tests for intermediate compounds in the synthesis of glutamine. It was not possible to detect any formation of an acyl phosphate when no 'glutamyl acceptor' was added to the incubation medium. Addition of hydroxylamine after the enzyme was incubated with glutamate and ATP and then inactivated by the addition of $0.005 \mathrm{M}$-sodium fluoride did not give a hydroxamic acid. As shown previously there was no liberation of phosphate from ATP unless a glutamyl acceptor such as ammonia was present. Highly labile phosphate derivatives such as acyl phosphates would appear as inorganic phosphate in the estimation by the Fiske \& Subbarow method.

\section{DISCUSSION}

The results show that glutamine is synthesized according to the following equation:

$$
\begin{aligned}
\text { glutamate + ATP + ammonia } & \\
& \rightarrow \text { glutamine + ADP + phosphate. }
\end{aligned}
$$

It is not yet certain whether one or more enzymes are involved in this reaction. Possibly a transfer of phosphate from ATP to glutamic acid occurs first and the resulting $\gamma$-glutamyl phosphate then reacts with ammonia to form glutamine and inorganic phosphate. So far, however, it has not been possible to demonstrate such an intermediate compound.
The discovery of a very active glutamine-forming system in typical 'asparagine type' plants is surprising and gives additional support to the suggestion by Street (1949) that the classical conception of asparagine and glutamine plants adopted by Schultze is no longer tenable. Presumably the glutamine is rapidly used in the asparagine plants since little is found to accumulate (Chibnall, 1939).

\section{SUMMARY}

1. The purification of an enzyme system from sheep brain which synthesizes glutamine from glutamate and ammonia in the presence of adenosinetriphosphate (ATP) is described. Inorganic phosphate is liberated in the reaction.

2. The system is specific towards L-glutamate and ATP. Ammonia can be replaced by hydroxylamine and hydrazine but not by organic bases. No reaction occurs in the absence of such 'glutamyl acceptors'.

3. The system is activated by $\mathrm{Mg}^{++}$and $\mathrm{Mn}^{++}$. Higher concentrations of the latter inhibit.

4. $\mathrm{Ca}^{++}$, adenosinediphosphate, the sulphoxide from methionine, fluoride and $p$-chloromercuribenzoate inhibit the synthesis of glutamine.

5. The system has been found in extracts from lupin seedlings. It has not been possible so far to demonstrate an analogous asparagine-forming system.

The author wishes to thank Prof. M. Dixon, F.R.S., and Dr E. C. Webb for the valuable advice and criticism which they have given during the course of this work. Thanks are also due to the Medical Research Council for a personal grant.

\section{REFERENCES}

Archibald, R. M. (1945). Chem. Rev. 37, 161.

Askonas, B. A. (1950). Biochem. J. 48, 42.

Bailey, K. (1942). Biochem. J. 36, 121.

Bailey, K. (1949). Biochem. J. 45, 479.

Chibnall, A. C. (1939). Protein Metabolism in the Plant,

New Haven: Yale University Press.

Elliott, W. H. (1948). Nature, Lond., 161, 128.

Elliott, W. H. (1949). lst Int. Congr. Biochem. Abstr. p. 574.

Elliott, W. H. \& Gale, E. F. (1948). Nature, Lond., 161, 129.

Fiske, C. H. \& Subbarow, Y. (1925). J. biol. Chem. 66, 375.

François, M. (1907). C.R. Acad. Sci., Paris, 144, 567.
Kerr, S. E. (1941). J. biol. Chem. 139, 121.

Krebs, H. A. (1935). Biochem. J. 29, 1951.

Lipmann, F. \& Tuttle, L. C. (1945). J. biol. Chem. 159, 21.

Needham, D. M. (1942). Biochem. J. 36, 113.

Speck, J. F. (1947). J. biol. Chem. 168, 403.

Speck, J. F. (1949a). J. biol. Chem. 179, 1387.

Speck, J. F. (1949b). J. biol. Chem. 179, 1405.

Street, H. E. (1949). Advanc. Enzymol. 8, 391.

Toennies, E. \& Kolb, J. J. (1939). J. biol. Chem. 128, 399.

Vickery, H. B., Pucher, G. W. \& Clark, H. E. (1936). J. biol.

Chem. 109, 39. 